\title{
STANDPUNKT
}

\section{Peinliche Machtspiele}

\author{
Monika Frommel
}

$\mathrm{D}$ ie hier abgedruckten 12 Fragen von Frieder Dünkel zur geplanten Verlagerung der Kompetenz für das Strafvollzugsrecht wurden der Bundesjustizministerin und den rechtspolitischen Sprechern der politischen Parteien vorgelegt. Nur Herr Röttgen von der CDU hat sich mit den Argumenten auseinandergesetzt. Die anderen schweigen. Die Bundesjustizministerin ließ über ihre Pressestelle verlautbaren, dass sie sich derzeit zu keiner Antwort in der Lage sehe. An zu engen Zeitvorgaben hat dies nicht gelegen. Was also ist der Hintergrund dieses peinlichen Machtspiels?

Zugegeben, die Föderalismusreform ist ein wichtiges Anliegen und eine klare Abgrenzung der Zuständigkeiten des Bundes und der Länder wünschenswert. Fraglich ist nur, ob ausgerechnet der Strafvollzug sich für eine solche Veränderung der Zuständigkeiten eignet? Das materielle und prozessuale Strafrecht, die Prinzipien und Unterschiede zwischen Erwachsenen- und Jugendstrafrecht, all dieses ist zurzeit noch unstreitig bundesrechtlich $\mathrm{zu}$ regeln. Landesstrafrechtliche Besonderheiten sind dort aus gutem Grund seit vierzig Jahren so gut wie bedeutungslos. Außerdem sind alle mit diesem scharfen Instrument der formellen Sozialkontrolle zusammenhängenden Regelungen nicht-strafrechtlicher Art primär eine Angelegenheit des Bundes, was etwa bei der Entkriminalisierung und alternativen Kontrolle von drogenabhängigen Straftätern bedeutsam ist und was für ein flexibles modernes Interventionsrecht immer bedeutsamer wird (Annexkompetenz).

Nicht zuletzt hat auch das Bundesverfassungsgericht bei seiner Entscheidung zu den mittlerweile bundesrechtlich überholten Landespolizeigesetzen zur nachträglichen Sicherungsverwahrung bestätigt, dass es Überschneidungen gibt zwischen Materien wie dem Polizeirecht, das den Ländern zugewiesen ist, und dem herkömmlich weiten Begriff des zweispurigen Strafrechts. Solche Widersprüche sind aber zugunsten der Bundeskompetenz für ein Strafrecht im weiten Sinne aufzulösen. Es bestand also zwar ein Anlass zu Reformüberlegungen, aber nur nach reiflicher Überlegung; denn die Folgen einer Änderung der Gesetzgebungskompetenz sind sehr weit reichend und bedürfen der fachlichen Debatte in allen Ländern und Fachgremien.

Aber selbst wenn man einmal annimmt, es seien fachliche Gründe gewesen für die vorgeschlagene Kompetenzverlagerung beim Strafvollzugsrecht, dann bleibt dennoch das konkret gewählte Verfahren mehr als unverständlich. Wieso wird an allen Fachvertretern, an den Rechtspolitikern aller Fraktionen und an der Justizminister(innen)konferenz vorbei eine einsame Entscheidung in einem Gremium getroffen, dem zu dieser Frage jedenfalls kein entsprechender
Klärungsprozess im Strafvollzugsausschuss und in der JuMiKo vorangegangen ist. Manche Länder mögen diesen Zuwachs an Kompetenzen zunächst einmal begrüßen, aber keineswegs die Länder, welche noch an einem effektiven Resozialisierungsvollzug interessiert sind. Denn schon jetzt gilt die traurige Regel, dass jeder entwichene Häftling auf Landesebene den oder die Justizministern in Bedrängnis bringt. In einer Mediendemokratie führen spektakuläre Einzelfälle nun einmal zu Forderungen an die Gesetzgebung und ggf. zu Gesetzesänderungen in Permanenz. Außerdem ist das populistische Gedächtnis

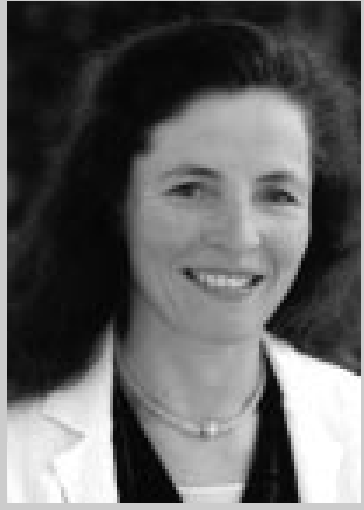

Prof. Dr. Monika Frommel ist Schriftleiterin dieser Zeitschrift notorisch schwach und verlangt kurz hintereinander nach jedem spektakulären Einzelfall (fast) dieselben Änderungen. Bislang blieb es in solchen Fällen bei Durchführungsregelungen unterhalb des StVollzG, die Fachaufsicht mag vertieft und die Sicherheitsstandards verschärft werden, aber an den Prinzipien eines resozialisierenden Strafvollzugs konnte nicht so leicht gerüttelt werden. Künftig würde sich das ändern.

Herr Röttgen hat gegenüber dieser Zeitschrift bekundet, dass es über alle Fraktionen hinweg erhebliche Bedenken gegen diesen Vorschlag des Justizministeriums gibt, der erstmals in der Föderalismuskommission geäußert wurde. Die Zahl der Unterzeichner unter dem hier abgedruckten Aufruf belegt, dass die Fachvertreter in den Universitäten und Fachhochschulen vehement gegen diesen Vorschlag eintreten. Wie Praktiker dazu stehen wissen wir nicht, da es wie gesagt keine Debatte gegeben hat. Völlig offen bleibt nun auch, wie sich dieser Vorschlag auf die geplante Novellierung des Jugendstrafvollzugs und den U-Haftvollzug auswirken wird.

Die Bundesministerin der Justiz versucht nun das Scheinwerferlicht, das sie bei der Föderalismusdebatte angeknipst hat, beim Strafvollzug wieder auszumachen und verweigert sich jeder Begründung. Ich halte dies für einen Skandal, zumal jeder Verständnis gehabt hätte für eine diplomatische Antwort, selbst ein Ausweichen in der Sache wäre nachvollziehbar gewesen, wenn wenigstens deutlich geworden wäre, dass der Verfahrensfehler korrigiert, die JuMiKo eingeschaltet und die abgekürzte Diskussion nun nachgeholt wird. Zeit dafür ist genug. 